\title{
Research on the Key Technology of Preparation of Ginkgo Biloba, Momordica Charantia and Chitosan Oral Liquid
}

\author{
Lin $\mathrm{Niu}^{1}$, Shuping $\mathrm{Li}^{2}$, Kaiyan $\mathrm{Li}^{3}$, Jinshuang $\mathrm{Qi}^{4}$, Yanlin $\mathrm{Liu}^{4}$, Guangyu Liu ${ }^{* 4}$ \\ ${ }^{1}$ Jiangsu Agri-animal Husbandry Vocational College, Taizhou, Jiangsu, 225300, China \\ ${ }^{2}$ Jiamusi University, Jiamusi, Heilongjiang, 154007, China \\ ${ }^{3}$ Jinling Institute of Technology, Nanjing, Jiangsu, 210046, China \\ ${ }^{4}$ CSPC Zhongnuo Pharmaceutical Co., Ltd., Taizhou, Jiangsu, 225312, China)
}

\begin{abstract}
*Corresponding Author: Liu Guangyu, (1977), male, senior engineer, master of engineering. Research direction: International Pharmaceutical Engineering Management..
\end{abstract}

\begin{abstract}
Momordica charantia polysaccharide and chitosan as raw materials, and then we took the ratio of Ginkgo flavone, Momordica charantia polysaccharide and chitosan and the amount of xylitol and citric acid as the main factors to carry out single factor experiment and orthogonal test. The results shows that the best conditions of Ginkgo biloba, Momordica charantia and chitosan oral liquid: The ratio of Ginkgo flavone solution, Momordica charantia polysaccharide solution and chitosan solution is 10ml: 30ml: 20ml, and the addition of xylitol is $10 \%$ and the addition of citric acid is $0.3 \%$. On this basis, the single factor test and orthogonal test were carried out with the ratio, addition amount and $\mathrm{pH}$ value of xanthan gum, EDTA-2Na and CMC-Na composite stabilizers as the main factors. The results shows that the optimal ratio of xanthan gum, EDTA-2Na and CMC-Na is 2: 1: 2. When the addition amount is $0.35 \mathrm{~g}$ and the $\mathrm{pH}$ is 5.5, we can prepare a brown clear Ginkgo biloba, Momordica charantia and chitosan oral liquid with soft flavor and uniform color.
\end{abstract}

Keywords: Ginkgo flavone; Momordica charantia polysaccharide; chitosan; oral liquid; stability

\section{INTRODUCTION}

Ginkgo biloba L. belongs to Ginkgoaceae and they are deciduous trees. It is the oldest relic plant left after the quaternary glaciation. It is one of the few plants that have maintained the ecological characteristics of 200 million years ago and survives, so it is called "living fossil". The chemical constituents of Ginkgo biloba are various, including flavonoids, terpenoids, alkaloids, phenols, polyisoprenols, etc.

Momordica charantia belongs to Cucurbitaceae and Momordica. It is an annual climbing herb, which is also called Laiputao, Jinlizhii, bitter gourd, etc ${ }^{[2]}$. The chemical constituents of Momordica charantia involve glycosides, terpenes, steroids, lipids, sugars, flavonoids and so on. Ginkgo biloba and balsam pear have many active ingredients, which have great advantages and potential in the treatment of diabetes

Chitosan is increasingly used as a clarifying agent in oral liquids because it can retain high active International Journal of Medicinal Plants and Natural Products (IJMPNP) 
ingredients and its clarifying effect has been confirmed. ${ }^{[3]}$. Moreover, chitosan also has many physiological activities, such as it can control cholesterol, inhibit cell activity, prevent and control hypertension, absorb and excrete heavy metals, and in addition, it even has immune effect.

Diabetes mellitus is a metabolic disease characterized by hyperglycemia, which is harmful to human health all over the world. It can cause a variety of complications, such as cardiovascular diseases, nephropathy, and retinopathy and so on, which brings burden to our daily life ${ }^{[4]}$.

The overall incidence of diabetes in the world has been on the rise. According to statistics, there are about 366 million diabetes patients in the world, and it is estimated that, by 2030, the number will rise to 552 million ${ }^{[5]}$. More than $90 \%$ of them are type-2 diabetes mellitus (T2M) ${ }^{[6]}$.

At present, at home and abroad, the methods of controlling blood glucose and blood lipid are mainly concentrated in the field of traditional Chinese and Western medicine treatment. The treatment methods include injecting insulin and taking hypoglycemic drugs orally, but the drugs can cause some side effects to a certain extent, and also induce some new diseases, which brings new problems for the treatment of hyperglycemia patients. In contrast, using natural plant active ingredients to control blood glucose is better, the side effects are small, and it can effectively delay the occurrence of complications ${ }^{[7]}$. Natural plant resources have high safety, so the preparation of functional food with hypoglycemic effect by extracting effective components from them and optimizing the combination is a hot spot in food science research, which has broad application prospects. The purpose of this study is to: extract Ginkgo flavone, Momordica charantia polysaccharide and chitosan as raw materials to optimize the compound, and then use a certain process to prepare a good-flavor and stable oral liquid with hypoglycemic function.

\section{MATERIALS, INSTRUMENTS, REAGENTS}

\subsection{Experimental Materials}

Ginkgo biloba, food grade, Taizhou Jitai Agricultural Products Co., Ltd.; Momordica charantia, food grade, Yangling Ciyuan Biotechnology Co., Ltd.; shrimp and crab shell, food grade, Shuanglong agricultural market in Hailing District, Taizhou City; xylitol, food grade, Shanghai Meilian Biology Co., Ltd.; potassium sorbate, food grade, Sinopharm Chemical Reagent Co., Ltd.

\subsection{Main Reagents}

Ethanol, phenol, concentrated sulfuric acid, dextran, sodium nitrite, aluminum nitrate, sodium hydroxide and hydrochloric acid. All of them are analytically pure. National Pharmaceutical Group Co., Ltd. Ultrapure water, grade 3, Animal Products Deep Processing Engineering Technology Research and Development Center of Jiangsu Province

\subsection{Main Instruments and Equipment}

Xl-02A miniature Chinese herbal medicine plant pulverizer, Nanjing Xuzhong Technology Co., Ltd.; ZF-20L vacuum suction filter, Shenzhen Sanli Chemical Co., Ltd.; 80-2A high-speed centrifuge, Changzhou Chunqiu Electronic Instrument Co., Ltd.; RE-5203 rotary evaporator, Shanghai Yarong biochemical instrument factory; HH-S2 digital-display water bath, Jincheng Guosheng experimental instrument factory, Jintan City, Jiangsu Province; 202-0A electric constant temperature drying oven, Shanghai Nuo Ding Instrument and Equipment Co., Ltd.; AL204 electronic balance, Shanghai Zhitai Electronic Technology Co., Ltd.; UV-5200 ultraviolet spectrophotometer, Shenzhen Green Ecological Technology Co., Ltd.; D101 macroporous adsorption resin, Zhengzhou Qinshi Technology Co., Ltd.; YT-TQ vacuum degasser, Hangzhou Yian Mechanical Equipment Co., Ltd. 


\section{EXPERIMENTAL METHODS}

\subsection{Extraction Methods for Ginkgo Biloba Leaf Extract}

\subsubsection{Technological process}

Ginkgo powder $\rightarrow$ extract Ginkgo flavonoids with ethanol $\rightarrow$ remove ginkgolic acid $\rightarrow$ Low-acid Ginkgo biloba leaf extract.

\subsubsection{Key points of operation}

(1) Dry and crush ginkgo leaves and let them pass through 100-meshes sieve. Accurately weigh $3.00 \mathrm{~g}$ ginkgo powder into a beaker, add $60 \%$ ethanol at the solid-liquid ratio of 1:80, and extract for $30 \mathrm{~min}$ at $50^{\circ} \mathrm{C}$ and $60 \mathrm{~W}$ ultrasonic power ${ }^{[9-10]}$.

(2) Reduce the pressure, recover the ethanol, add water to 3 times the amount of the medicinal material, stand still, filter it, then use D101 macroporous adsorption resin, wash the column with 5 times of water, and desorb with $70 \%$ ethanol of 3 times the volume of resin bed, collect the part with dark color, reduce the pressure, recover the ethanol, and concentrate to a certain volume, use appropriate amount of organic solvent to extract, reduce the pressure of the liquid layer, recover the organic solvent, concentrate it to thick paste, and dry and crush it at $70{ }^{\circ} \mathrm{C}$ under vacuum condition.

\subsection{Extraction Method for Momordica Charantia Polysaccharide}

\subsubsection{Technological process}

Slice Momordica charantia $\rightarrow$ dry and crush $\rightarrow$ Momordica charantia powder $\rightarrow$ ethanol reflux (remove monosaccharides, oligosaccharides, glycosides and other impurities) $\rightarrow$ suction filtration and get filter residue $\rightarrow$ ultrasonic extraction of filter residue with water $\rightarrow$ centrifugation of filtrate for impurity removal $\rightarrow$ take supernatant $\rightarrow$ crude polysaccharide solution.

\subsubsection{Key points of operation}

(1) Slice fresh Momordica charantia, dry, grind into powder, let it pass through 40-meshes sieve, $80 \%$ ethanol reflux and extraction at $90{ }^{\circ} \mathrm{C}$ for 2 times, suction filtration, get the filter residue.

(2) Add ultrapure water (tertiary water) according to the solid-liquid ratio of 1:50, extract by ultrasonic at $96^{\circ} \mathrm{C}$ for $230 \mathrm{~min}$ [8], centrifuged by $6000 \mathrm{r} / \mathrm{min}$ centrifuge for $10 \mathrm{~min}$, take supernatant.

\subsection{Extraction Method for Chitosan Extract}

\subsubsection{Technological process}

Shrimp and crab shells $\rightarrow$ use dilute alkali solution to soak repeatedly to remove protein $\rightarrow$ water washing $\rightarrow$ acid soaking until no bubble is produced to obtain chitin $\rightarrow$ bleaching $\rightarrow \mathrm{NaOH}$ boiling for 3-4h for chitin deacetylation $\rightarrow$ wash $\rightarrow$ dry $\rightarrow$ chitosan.

\subsubsection{Key points of operation}

(1) Use dilute alkali to treat shrimp and crab shells to remove protein. Wash, and add hydrochloric acid to remove calcium chloride to obtain chitin.

(2) Use 40\% - 50\% hot sodium hydroxide for chitin deacetylation, wash it with water, and dry it to get chitosan.

\subsection{Preparation Method of Oral Liquid}

3.4.1 Preparation process for oral liquid 
The mixing and preparation of Ginkgo flavone, Momordica charantia polysaccharide and chitosan $\rightarrow$ concentration $\rightarrow$ homogenization $\rightarrow$ degassing $\rightarrow$ sterilization $\rightarrow$ bottling $\rightarrow$ cooling $\rightarrow$ finished products.

3.4.2 Key points for oral liquid preparation

(1) Preparation of Ginkgo biloba extraction solution

Take distilled water and heat it, add the extract of Ginkgo biloba leaves under constant stirring to make the total flavonoid solution, then add monosaccharide, adjust $\mathrm{pH}$, filter, determine the content of total flavonoids of Ginkgo biloba in the filtrate, dilute with distilled water to $5.0 \mathrm{mg} / 10 \mathrm{ml}$ total flavonoids of Ginkgo biloba leaves, and mix well to prepare the standby solution of Ginkgo biloba leaf extract.

(2) Preparation of Momordica charantia polysaccharide extraction solution. Dissolve the Momordica charantia polysaccharide and water at 1:50 to obtain the solution, filter, and determine the content of Momordica charantia polysaccharide in the filtrate. Dilute with distilled water to $3.0 \mathrm{mg} / 10 \mathrm{ml}$ Momordica charantia polysaccharide, and mix well to prepare the standby solution of Momordica charantia polysaccharide.

(3) Preparation of chitosan extraction solution. Accurately weigh appropriate amount of chitosan, add $1 \%$ glacial acetic acid, stir and dissolve until the mixture is uniform, and then get the chitosan standby solution of $2 \%$ concentration.

(4) Mixing and preparation. Mix the Ginkgo biloba extraction solution, Momordica charantia extraction solution, chitosan extraction solution, xylitol and citric acid, and select the best combination by orthogonal test.

(5) Concentration. At $-0.06 \mathrm{MPa}$ and $80^{\circ} \mathrm{C}$, reduce the pressure and concentrate.

(6) Homogenization. The concentrated solution is homogenized by high-pressure homogenizer, and the pressure is $21 \mathrm{MPa}$. The homogenized oral liquid was degassed by vacuum degasser at $40{ }^{\circ} \mathrm{C}$ and the vacuum degree is $90.7 \mathrm{kPa}$.

(7) Sterilization. After degassing, sterilized the oral liquid with boiling water, that is, the temperature was $100{ }^{\circ} \mathrm{C}$ and the time was $6-9 \mathrm{~min}$. After sterilization, quickly cool it to about $38^{\circ} \mathrm{C}$, bottle, and seal in time.

\subsection{Single Factor Test for Ginkgo Biloba, Momordica Charantia and Chitosan Oral Liquid}

3.5.1 Effect of different ratio of Ginkgo flavone solution, Momordica charantia polysaccharide solution and chitosan solution on the quality of oral liquid

Combine the Ginkgo flavone solution, Momordica charantia polysaccharide solution and chitosan solution in different volume ratios. Group A: $10 \mathrm{ml}: 20 \mathrm{ml}: 20 \mathrm{ml}$; group B: $10 \mathrm{ml}: 20 \mathrm{ml}: 30 \mathrm{ml}$; group C: $10 \mathrm{ml}: 30 \mathrm{ml}: 10 \mathrm{ml}$; group D: $10 \mathrm{ml}: 30 \mathrm{ml}: 20 \mathrm{ml}$; Group E: $10 \mathrm{ml}: 30 \mathrm{ml}: 30 \mathrm{ml}$; Group F: 20ml : $10 \mathrm{ml}: 10 \mathrm{ml}$; group G: $20 \mathrm{ml}: 10 \mathrm{ml}: 20 \mathrm{ml}$. Evaluate the effect of different combinations on the quality of oral liquid.

\subsubsection{Effect of xylitol addition amount on the quality of oral liquid}

Added $2 \%, 4 \%, 6 \%, 8 \%, 10 \%, 12 \%, 14 \%$ xylitol to the oral liquid respectively. Evaluat the effect of different xylitol addition amount on the quality. 


\subsubsection{Effect of citric acid addition amount on the quality of oral liquid}

Added $0.05 \%, 0.1 \%, 0.15 \%, 0.2 \%, 0.25 \%, 0.3 \%, 0.35 \%$ citric acid to the oral liquid respectively. Evaluat the effect of different citric acid addition amount on the quality.

\subsection{Orthogonal Test of Ginkgo Biloba, Momordica Charantia and Chitosan Oral Liquid}

On the basis of single factor test, carry out the orthogonal test of the ratio of Ginkgo biloba, Momordica charantia and chitosan oral liquid (Table 1)

Table1. Factor level design

\begin{tabular}{|l|l|l|l|}
\hline \multirow{2}{*}{ Level } & \multicolumn{2}{|l|}{ Factor } & C Citric acid /\% \\
\cline { 2 - 4 } & $\begin{array}{l}\text { A The ratio of Ginkgo biloba, Momordica } \\
\text { charantia and chitosan solution } / \mathrm{ml}\end{array}$ & B Xylitol /\% & 0.1 \\
\hline 1 & $10 \mathrm{~mL}: 30 \mathrm{~mL}: 10 \mathrm{~mL}$ & 6 & 0.2 \\
\hline 2 & $10 \mathrm{~mL}: 30 \mathrm{~mL}: 20 \mathrm{~mL}$ & 8 & 0.3 \\
\hline 3 & $10 \mathrm{~mL}: 30 \mathrm{~mL}: 30 \mathrm{~mL}$ & 10 & \\
\hline
\end{tabular}

\subsection{Stability Test}

\subsubsection{Effects of different ratios of stabilizers on the stability of oral liquid}

The mass ratio of xanthan gum : edta-2na : CMC Na are respectively $1: 3: 2,1: 3: 3,2: 1: 1,2: 1$ : $2,2: 1: 3,2: 2: 1,2: 2: 2$. Evaluate the effects of different stabilizer ratios on the stability of oral liquid.

\subsubsection{Effect of the addition amount of compound stabilizer on the stability of oral liquid}

Add $0.2 \mathrm{~g}, 0.25 \mathrm{~g}, 0.3 \mathrm{~g}, 0.35 \mathrm{~g}, 0.4 \mathrm{~g}, 0.45 \mathrm{~g}, 0.5 \mathrm{~g}$ compound stabilizer into the oral liquid respectively, and investigate the influence of the addtion amount of stabilizer on the stability of oral liquid.

\subsubsection{Effect of compound stabilizer on the stability of oral liquid under different $\mathrm{pH}$ conditions}

Adjust the $\mathrm{pH}$ of oral liquid to 4.0, 4.5, 5.0, 5.5, 6.0, 6.5, 7.0 one by one. Investigate the effect of compound stabilizer on the stability of oral liquid under different $\mathrm{pH}$ conditions.

\subsubsection{Determination of stability coefficient}

Take 5ml of well-mixed sterilized compound oral liquid (shake thoroughly), put it into a 50ml volumetric flask, precise the volume with distilled water, shake well, and measure the absorbance A1 at the maximum absorption wavelength with spectrophotometer. Then take $10 \mathrm{ml}$ of compound oral liquid and put it into a high-speed centrifuge, centrifuge it at a speed of 2000r/min for $10 \mathrm{~min}$, take 5 $\mathrm{ml}$ of supernatant, dilute 10 times with the same method, shake up, measure the absorbance $\mathrm{A} 2$ at the maximum absorption wavelength, and calculate the stability coefficient $\mathrm{R}$ of the compound oral liquid. The higher $\mathrm{R}$, the more stable the compound beverage.

The calculation formula is as follows:

$$
R=\frac{A_{2}}{A_{1}}
$$

In this formula: $\mathrm{R}$ is the stability coefficient

$\mathrm{A}_{1}$ is the absorbance of oral liquid before centrifugation 
$\mathrm{A}_{2}$ is the absorbance of the supernatant of the oral liquid after centrifugation

\subsection{Design for the Orthogonal Test on Stability of Ginkgo Biloba, Momordica Charantia and Chitosan Oral Liquid}

Design for the orthogonal test on stability of Ginkgo biloba, Momordica charantia and chitosan oral liquid (Table 2)

Table2. Factor level design

\begin{tabular}{|c|c|c|c|}
\hline \multirow[b]{2}{*}{ Level } & \multicolumn{3}{|l|}{ Factor } \\
\hline & Ratio of stabilizer (D) $/ \mathrm{ml}$ & $\begin{array}{l}\text { Addition amount of stabilizer (E) } \\
/ \mathrm{g}\end{array}$ & $\mathrm{pH}$ value $(\mathrm{F})$ \\
\hline 1 & $2: 1 ; 1$ & 0.3 & 5.0 \\
\hline 2 & $2: 1: 2$ & 0.35 & 5.5 \\
\hline 3 & $2: 1: 3$ & 0.4 & 6.0 \\
\hline
\end{tabular}

\subsection{Sensory Evaluation Method}

Invite 10 food-speciality persons with normal sensory function to form a sensory evaluation team. Use the comprehensive scoring method to evaluate the color, smell, flavor and impurities of Ginkgo biloba, Momordica charantia and chitosan oral liquid. By integrating these four factors, we can get the final score results (Table 3).

Table3. Sensory evaluation of Ginkgo biloba, Momordica charantia and chitosan oral liquid

\begin{tabular}{|c|c|c|}
\hline Item & Evaluation standard & Score \\
\hline \multirow[t]{4}{*}{ Color (20) } & The color is even and brown & $(16 \sim 20)$ \\
\hline & $\begin{array}{l}\text { The color is slightly poor, basically uniform, and the color is slightly } \\
\text { dark }\end{array}$ & $(11 \sim 15)$ \\
\hline & $\begin{array}{l}\text { The color is slightly poor, basically uniform, and the color is slightly } \\
\text { dark }\end{array}$ & $(6 \sim 10)$ \\
\hline & The color is dark, uneven, dark black & $(<6)$ \\
\hline \multirow[t]{4}{*}{ Smell (20) } & $\begin{array}{l}\text { The smeall of flavonoid and polysaccharide extraction solution is } \\
\text { harmonious and uniform }\end{array}$ & $(16 \sim 20)$ \\
\hline & The flavor of flavonoid and polysaccharide is slightly light & $(11 \sim 15)$ \\
\hline & The flavor of flavonoid and polysaccharide is slightly light & $(6 \sim 10)$ \\
\hline & A certain flavor is too strong, which is seriously out of harmony & $(<6)$ \\
\hline \multirow[t]{4}{*}{ Flavor (30) } & The flavor is soft and has no peculiar smell & $(26 \sim 30)$ \\
\hline & The flavor is relatively soft and has no peculiar smell & $(21 \sim 25)$ \\
\hline & The flavor is a little bad and has peculiar smell & $(16 \sim 20)$ \\
\hline & The flavor is a little bad and has serious peculiar smell & $(<16)$ \\
\hline \multirow[t]{4}{*}{ Impurity (30) } & $\begin{array}{l}\text { Clear, with a small amount of allowed flocculent precipitate, no visible } \\
\text { foreign precipitate }\end{array}$ & $(26 \sim 30)$ \\
\hline & $\begin{array}{l}\text { Relatively clear, with some flocculent precipitate, no visible foreign } \\
\text { precipitate }\end{array}$ & $(21 \sim 25)$ \\
\hline & $\begin{array}{l}\text { Slightly clear, flocculent precipitate is more, and a small amount of } \\
\text { foreign precipitate } t \text { can be seen by eyes }\end{array}$ & $(16 \sim 20)$ \\
\hline & $\begin{array}{l}\text { Turbid, there is a lot of flocculent precipitate, eyes can see a lot of } \\
\text { foreign precipitate }\end{array}$ & $(<16)$ \\
\hline
\end{tabular}




\subsection{Methods of Analysis And Determination}

The determination of $\mathrm{pH}$ refers to Pharmacopoeia of the people's Republic of China; the determination of soluble solids refers to the General analysis method of beverages (GB12143-2008); the determination of total bacterial count refers to GB4789.2-2010. The determination of coliform group refers to GB4789.3-2010. The determination method of mold refers to GB4789.15-2016. The determination of Salmonella refers to GB4789.4-2010. The determination method of Staphylococcus aureus refers to GB4789.10-2010.

\section{RESULTS AND ANALYSIS}

\subsection{Single Factor Test on the Prescription of Compound Oral Liquid}

4.1.1 Effect of different ratio of Ginkgo flavone, Momordica charantia polysaccharide and chitosan on the quality of oral liquid

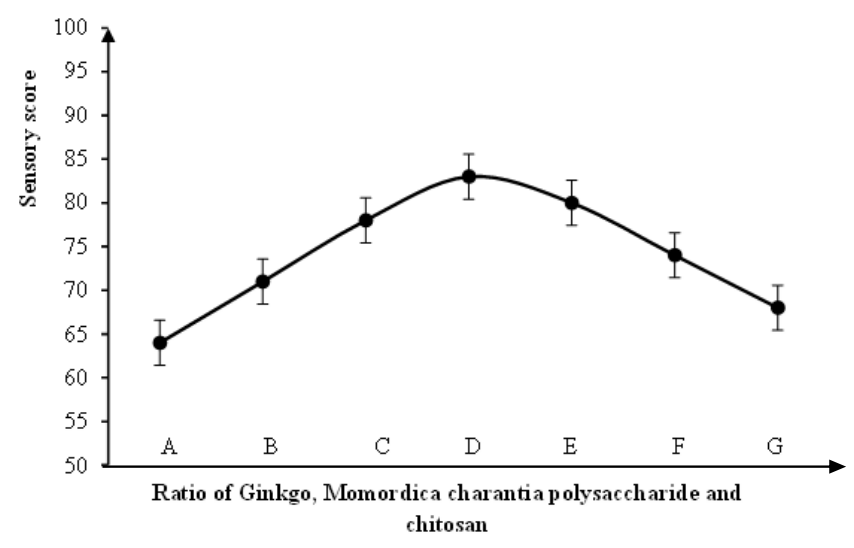

Figure1. Effect of different ratio of Ginkgo flavone solution, Momordica charantia polysaccharide solution and chitosan solution on the quality of oral liquid

Note: group A: 10ml : 20ml : 20ml; group B: 10ml :20ml :30ml; group C: $10 \mathrm{ml}: 30 \mathrm{ml}: 10 \mathrm{ml}$; group D: $10 \mathrm{ml}: 30 \mathrm{ml}: 20 \mathrm{ml}$; Group E: $10 \mathrm{ml}: 30 \mathrm{ml}: 30 \mathrm{ml}$; Group F: $20 \mathrm{ml}: 10 \mathrm{ml}: 10 \mathrm{ml}$; group G: $20 \mathrm{ml}: 10 \mathrm{ml}: 20 \mathrm{ml}$.

From group A to group D about the ratio of Ginkgo flavone, Momordica charantia polysaccharide and chitosan solutions, the sensory scores of oral liquid increase from 64 points to 83 points; from group D to group G, the sensory scores of oral liquid gradually decrease from 83 points to 68 points; therefore, when the ratio of Ginkgo flavone solution, Momordica charantia polysaccharide solution and chitosan solution is group D: $10 \mathrm{ml}: 30 \mathrm{ml}: 20 \mathrm{ml}$, the oral liquid has the best quality Good (Figure 1).

4.1.2 Effect of xylitol addition amount on the quality of oral liquid

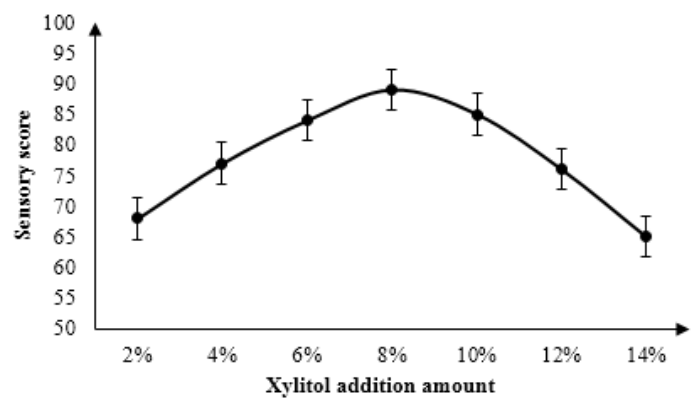

Figure2. Effect of xylitol addition amount on the quality of oral liquid 
When the addition amount of xylitol increases from $2 \%$ to $8 \%$, the sensory scores of oral liquid increase from 68 points to 89 points; when the addition amount of xylitol continues to increase from $8 \%$ to $14 \%$, the sensory scores of oral liquid decrease from 89 points to 65 points. Therefore, we can conclude that the optimal addition amount of xylitol corresponding to the highest sensory score of oral liquid is $8 \%$ (Figure 2).

\subsubsection{Effect of citric acid addition amount on the quality of compound oral liquid}

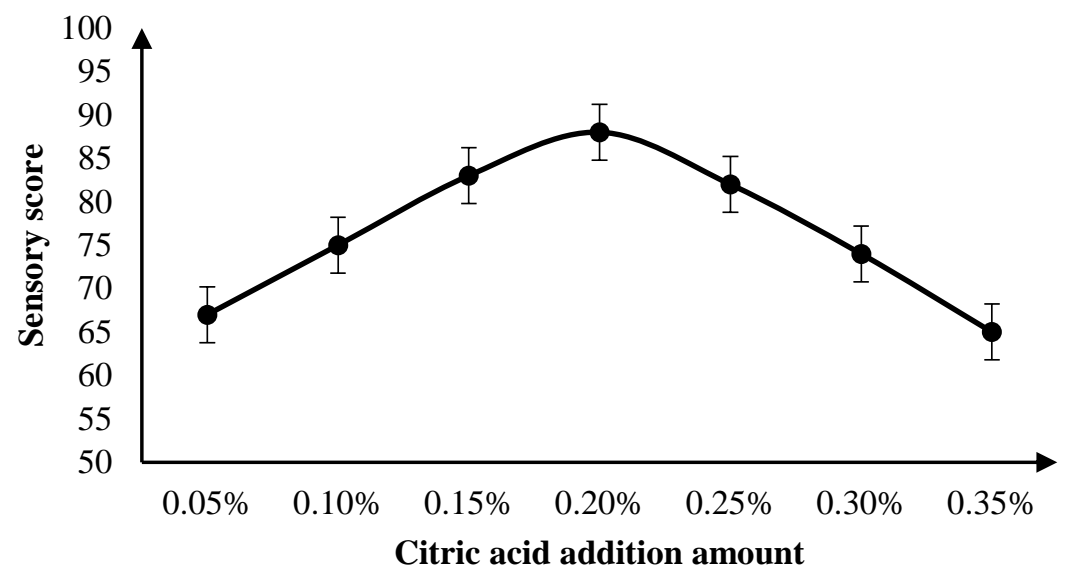

Figure3. Effect of citric acid addition amount on the quality of oral liquid

When the addition amount of citric acid increases from $0.05 \%$ to $0.2 \%$.( Figure 3 ), the sensory scores of oral liquid gradually increase from 67 points to 88 points; when the addition amount of citric acid continues to increase from $0.2 \%$ to $0.35 \%$, the sensory scores of oral liquid gradually decrease from 88 points to 65 points. When citric acid is $0.2 \%$, the oral liquid has the highest sensory evaluation.

\subsection{Orthogonal test on the prescription of Ginkgo biloba, Momordica charantia and chitosan oral liquid}

The orthogonal test results of the prescription of Ginkgo biloba, Momordica charantia and chitosan oral liquid (Table 7).

Table7. The result analysis of orthogonal test

\begin{tabular}{|c|c|c|c|c|}
\hline \multirow[b]{2}{*}{ Test number } & \multicolumn{3}{|l|}{ Factor } & \multirow[b]{2}{*}{ Sensory score } \\
\hline & $\begin{array}{l}\text { A Ratio of Ginkgo biloba, } \\
\text { Momordica charantia and } \\
\text { chitosan extraction solution } \\
(\mathrm{mL})\end{array}$ & B Xylitol (\%) & C Citric acid (\%) & \\
\hline 1 & 1 & 1 & 1 & 65 \\
\hline 2 & 1 & 2 & 2 & 75 \\
\hline 3 & 1 & 3 & 3 & 80 \\
\hline 4 & 2 & 1 & 2 & 84 \\
\hline 5 & 2 & 2 & 3 & 86 \\
\hline 6 & 2 & 3 & 1 & 75 \\
\hline 7 & 3 & 1 & 3 & 78 \\
\hline 8 & 3 & 2 & 1 & 70 \\
\hline 9 & 3 & 3 & 2 & 78 \\
\hline
\end{tabular}


Research on the Key Technology of Preparation of Ginkgo Biloba, Momordica Charantia and Chitosan Oral Liquid

\begin{tabular}{|l|l|l|l|l|}
\hline K1 & 73 & 76 & 70 & \\
\hline K2 & 82 & 77 & 79 & \\
\hline K3 & 75 & 78 & 81 & \\
\hline R & 9 & 2 & 11 & \\
\hline
\end{tabular}

The intuitive analysis data in Table 7 shows that the order of influence of each factor is $\mathrm{C}$ citric acid addition > A ratio and addition amount of Ginkgo biloba, Momordica charantia and chitosan extraction solutions $>\mathrm{B}$ xylitol addition amount. According to the comparison of three levels of the same factor, it can be known that $\mathrm{A} 2>\mathrm{A} 3>\mathrm{A} 1, \mathrm{~B} 3>\mathrm{B} 2>\mathrm{B} 1, \mathrm{C} 3>\mathrm{C} 2>\mathrm{C} 3$. Therefore, the optimum technological conditions are $\mathrm{A} 2 \mathrm{~B} 3 \mathrm{C} 3$, that is, the ratio of Ginkgo biloba, Momordica charantia and chitosan is $10 \mathrm{ml}: 30 \mathrm{ml}: 20 \mathrm{ml}$, xylitol addition amount is $10 \%$ and citric acid addition amount is $0.3 \%$.

\subsection{Single factor test on stability of Ginkgo biloba, Momordica charantia and chitosan oral liquid}

4.3.1 Effect of stabilizer ratio on the stability of oral liquid

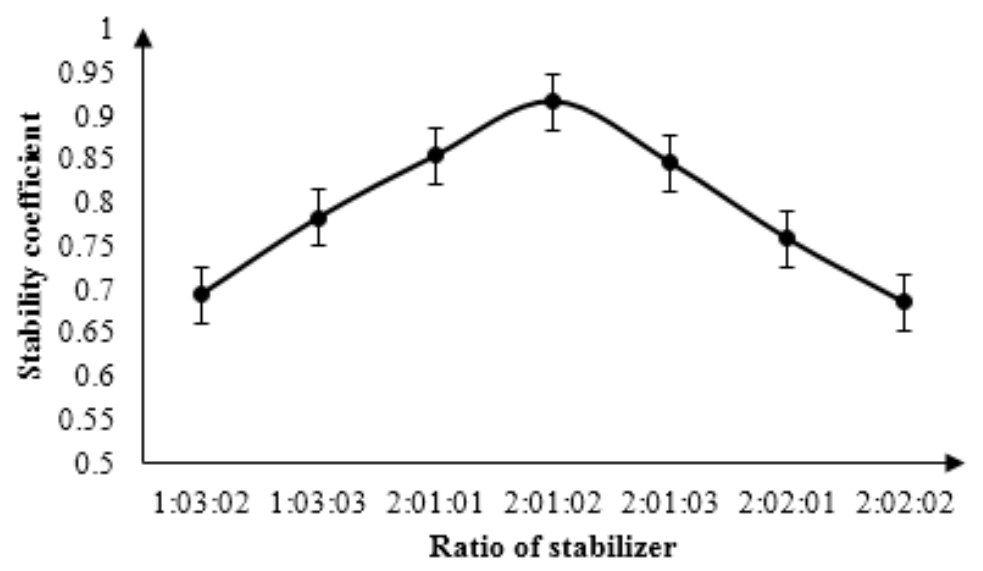

Figure4. Effect of stabilizer ratio on the stability of oral liquid

When the stability coefficient of the mixed oral liquid reached the highest of 0.915 , the optimal mass ratio of xanthan gum:EDTA-2Na :CMC-Na was 2:1:2 (Fig. 4).

4.3.2 Effect of stabilizer addition amount on the stability of oral liquid

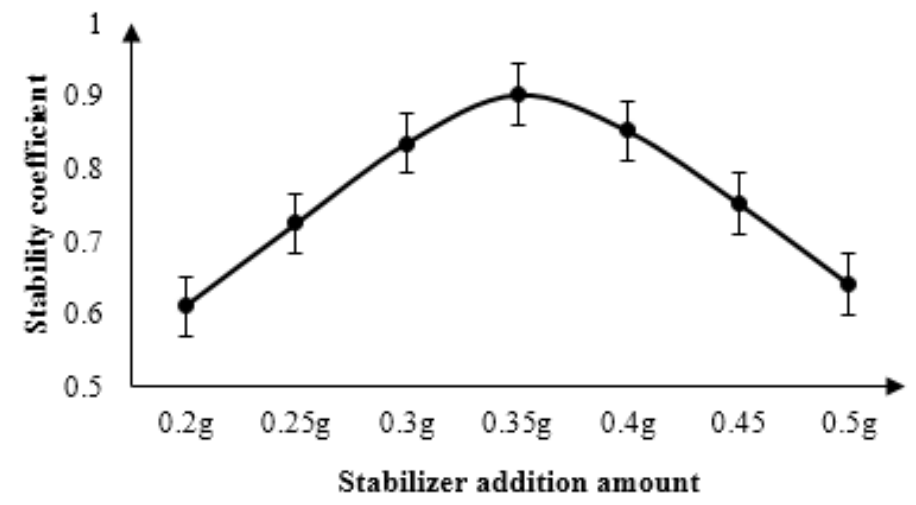

Figure5. Effect of stabilizer addition amount on the stability of oral liquid

When the stabilizer addition amount increases from $0.2 \mathrm{~g}$ to $0.35 \mathrm{~g}$, the stability coefficient increases from 0.610 to 0.902 ; when the stabilizer addition amount continues to increase from $0.35 \mathrm{~g}$ to $0.5 \mathrm{~g}$, the 
stability coefficient of oral liquid gradually decreases from 0.902 to 0.640 . Therefore, it can be known that when the stability coefficient of oral liquid reaches the highest value of 0.902 , the optimal addition amount of stabilizer is $0.35 \mathrm{~g}$ (Figure 5).

\subsubsection{Effect of stabilizers under different $p H$ conditions on the stability of oral liquid}

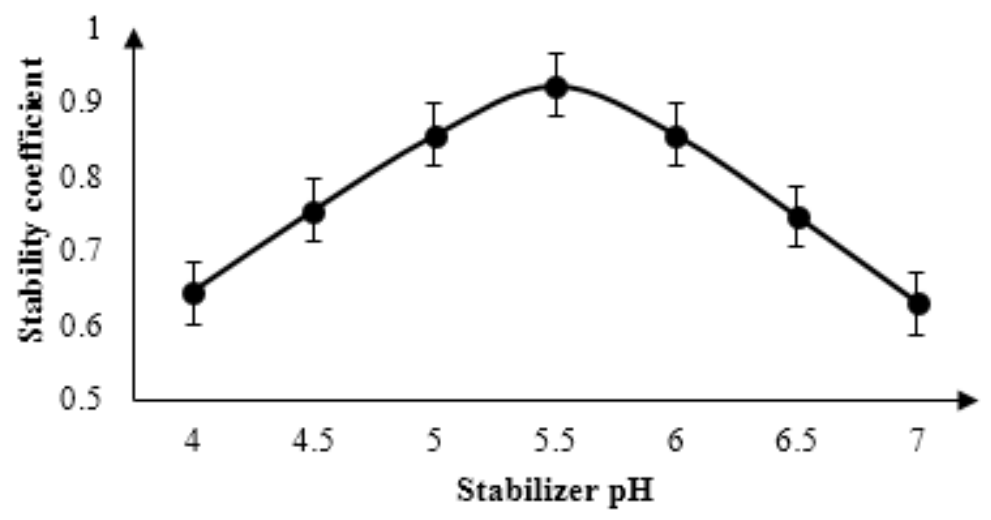

Figure6. Effect of compound stabilizer on oral liquid stability under different $\mathrm{pH}$ conditions

When the $\mathrm{pH}$ of oral liquid is adjusted from 4 to 5.5, the stability coefficient gradually increases from 0.644 to 0.922 ; when the $\mathrm{pH}$ continues to be adjusted from 5.5 to 7 , the stability coefficient gradually decreases from 0.922 to 0.629 . When $\mathrm{pH}$ is 5.5 , the stability coefficient of oral liquid reaches the highest of 0.922. Therefore, when $\mathrm{pH}$ is 5.5, the stabilizing effect of stabilizer is the best (Figure 6).

\subsubsection{Orthogonal test on stability of Ginkgo biloba, Momordica charantiaand chitosan oral liquid}

The result of the orthogonal test on stability of Ginkgo biloba, Momordica charantiaand chitosan oral liquid (Table 8).

Table8. The result analysis of orthogonal test

\begin{tabular}{|c|c|c|c|c|}
\hline \multirow[b]{2}{*}{ Test number } & \multicolumn{3}{|l|}{ Factor } & \multirow[b]{2}{*}{ Stability coefficient } \\
\hline & $\begin{array}{l}\mathrm{D}(\text { Ratio of } \\
\text { stabilizer })(\mathrm{mL})\end{array}$ & $\begin{array}{l}\text { E (Addition amount of } \\
\text { compound stabilizer ) }(\mathrm{g})\end{array}$ & $\mathrm{F}$ (pH of stabilizer) & \\
\hline 1 & 1 & 1 & 1 & 0.848 \\
\hline 2 & 1 & 2 & 2 & 0.892 \\
\hline 3 & 1 & 3 & 3 & 0.857 \\
\hline 4 & 2 & 1 & 2 & 0.891 \\
\hline 5 & 2 & 2 & 3 & 0.887 \\
\hline 6 & 2 & 3 & 1 & 0.878 \\
\hline 7 & 3 & 1 & 3 & 0.845 \\
\hline 8 & 3 & 2 & 1 & 0.859 \\
\hline 9 & 3 & 3 & 2 & 0.868 \\
\hline K1 & 0.866 & 0.861 & 0.862 & \\
\hline K2 & 0.885 & 0.879 & 0.884 & \\
\hline K3 & 0.857 & 0.868 & 0.863 & \\
\hline $\mathrm{R}$ & 0.028 & 0.018 & 0.022 & \\
\hline
\end{tabular}

The order of influence of each factor is $\mathrm{D}$ (the ratio of stabilizer) $>\mathrm{E}$ (compound stabilizer addition amount) $>\mathrm{F}$ (stabilizer $\mathrm{pH}$ ). According to the comparison of the three levels of the same factor, D2 > D1 $>$ D3, E2 $>$ E3 $>$ E1, F2 > F3 > F1 (Table 8). Therefore, the optimal process conditions are 
$\mathrm{D} 2 \mathrm{E} 2 \mathrm{~F} 2$, that is, the ratio of stabilizer is $2: 1: 2$, the addition amount of compound stabilizer is $0.35 \mathrm{~g}$, and the $\mathrm{pH}$ value of stabilizer is 5.5.

\subsection{Product Indexes Of Ginkgo Biloba, Momordica Charantia And Chitosan Oral Liquid}

\subsubsection{Sensory quality indexes}

Color: the product is natural brown of Ginkgo flavone solution, Momordica charantia polysaccharide solution and chitosan solution, and the color is uniform.

Smell: the flavors of flavonoid polysaccharide and chitosan are harmonious and consistent.

Flavor: the taste is delicate, the bitter taste of flavonoid polysaccharide is less, no other peculiar smell. Impurities: clear and transparent, with a small amount of precipitates easily dispersed after shaking, no visible foreign precipitates.

\subsubsection{Physical and chemical indexes}

Soluble solid content: 3.5\%; $\mathrm{pH}$ : 5.5.

\subsubsection{Microorganism index}

The total number of colonies (cells $/ \mathrm{ml}$ ) $<100$, in line with the national standard gb4789.2-2010;

Coliform group (number / 100ml) < 3, in line with the national standard GB4789.3-2010;

Mold < 20, in line with the national standard GB4789.15-2016;

Pathogenic bacteria (Staphylococcus aureus, Salmonella): no bacteria detected, in line with the national standards GB4789.4-2010 and GB4789.10-2010.

\section{CONCLUSION AND PROSPECT}

\subsection{Conclusion}

The results of single factor test of sensory evaluation shows that the ratio and addition amount of Ginkgo biloba, Momordica charantia and chitosan extraction solutions is $10 \mathrm{ml}: 30 \mathrm{ml}: 20 \mathrm{ml}$. The addition amount of xylitol is $8 \%$. It is the best addition amount of compound oral liquid. The addition amount of citric acid is $0.2 \%$. It is the best addition amount of compound oral liquid.

The results of orthogonal test shows that the best combination of sensory evaluation of compound oral liquid is $\mathrm{A} 2 \mathrm{~B} 3 \mathrm{C} 3$, that is, the ratio and addition amount of Ginkgo biloba, Momordica charantia and chitosan extraction solution was $10 \mathrm{ml}: 30 \mathrm{ml}: 20 \mathrm{ml}$, xylitol addition amount is $10 \%$, and citric acid addition amount is $0.3 \%$.

The results of stability single factor test shows that the optimum ratio of xanthan gum: EDTA-2Na :CMC-Na is $2: 1: 2$. The addition amount of compound stabilizer is $0.35 \mathrm{~g}$. It is the optimum addition amount of compound stabilizer. The $\mathrm{pH}$ of stabilizer is 5.5. It is the optimum $\mathrm{pH}$ value of the compound stabilizer.

The results of stability orthogonal test shows that the best combination of stability test conditions is $\mathrm{D} 2 \mathrm{E} 2 \mathrm{~F} 2$, that is, the ratio of xanthan gum :EDTA-2Na :CMC-Na is $2: 1: 2$, the addition amount of compound stabilizer is $0.35 \mathrm{~g}$, and the $\mathrm{pH}$ value of stabilizer is 5.5 .

\subsection{Prospect}

For this product, we only selected the main effective components, flavonoids and polysaccharides, as the evaluation indexes. In terms of other effective components, we should further study them, such as terpenoid lactones, saponins and other substances.

The flavonoids and polysaccharides extracted in this study did not verify the bioavailability. Therefore, we should further verify the pharmacological effects of flavonoids and polysaccharides on 
hypoglycemia, anti-tumor and improving immunity through animal experiments, so as to provide a comprehensive and accurate scientific basis for the further development and utilization of Ginkgo biloba, Momordica charantia and chitosan oral liquid.

In this paper, the preparation technology and stability of Ginkgo biloba, Momordica charantia and chitosan oral liquid were studied, which provided data reference for the future production process equipment and factory production. Due to the limited laboratory conditions, in this project, we only carried out small-scale tests. In the future, we can carry out large-scale tests to find and solve the problems that may appear in the actual production.

\section{ACKNOWLEDGMENT}

This work is supported by "Taizhou Science and Technology Supporting Plan Agriculture Project (TS201815); Taizhou Science and Technology Supporting Plan Social Development Project (TS201923); Scientific Research Project of Jiangsu Agri-animal Husbandry Vocational College (NSFHP 201907)(NSFTP201839) ; General Guidance Project of Jiangsu University Students' Practice and Innovation in 2019 (201912806012y)". We are very grateful to Zhengyun Wang, Junyan Zhang, Yuhan Zheng, Pengwei Xu, Ning Zhang, Xia Li, Fangyue Rong, Jinyong Zhang, Guorui Zhang, Si Chen, Yaxing Guo, Siyu Liu, Chen Liang, Guoai Lu for his technical support and help.

\section{REFERENCES}

[1] Wei Xueli, Qu Wei, Liang Jingyu. Research progress of Ginkgo biloba [J]. Strait Pharmaceutical Journal, 2013, 25 (2): 1-8

[2] Tian Yawei. A summary of research on Momordica charantia. Medical information, 2002, 15 (10): 619

[3] Hao Meimei. Preparation of Dendrobium candidum oral liquid and study on its bioavailability [D]. Tianjin University of science and technology, 2015

[4]Frayling MT. Genome-wide association studies provide new insights into type 2 diabetes aetiology. Genetics,2007,8:657-62.

[5]Colagiuri, R.,J. Brown, and K. Dain,Global Diabetes Plan 2011-202L 2011:International Diabetes Federation.

[6]Yang, W., et al., Prevalence of diabetes among men and women in China. New England Journal of Medicine, 2010. 362(12): p. 1090-1101.

[7] Zhang juzuo, Xu Qiaoling, Xu Junfei. Study on the detection of phenol research method for the determination of Momordica charantia polysaccharide content [J]. Food research and development, 2015 (36): $82-85$

[8] Liang Yan, Zhang Chuanjun, Lv Yanrong. Effect and mechanism of purslane polysaccharide on diabetic mice induced by high-fat diet combined with streptozotocin [J]. Food science, 2014 (35): 217-220

[9] Zheng Yunying, Zhang Yanjun, Zhong Shuming, Huang Baozhang, Gong Libing. Ultrasonic extraction of total flavonoids from Ginkgo leaves from Gingko tree [J]. Journal of Qinzhou University, 2013 (28): 35-39

[10] Shao Shengrong. Study on extraction, purification, preparation technology and quality of active components from leaves of Ginkgo leaves [D]. Zhejiang University, 2005

Citation: Guangyu Liu, et.al., (2020). "Research on the Key Technology of Preparation of Ginkgo Biloba, Momordica Charantia and Chitosan Oral Liquid". International Journal of Medicinal Plants and Natural Products (IJMPNP), 6(4), pp.38-49. https://doi.org/10.20431/2454-7999.0604005

Copyright: (0) 2020 Authors. This is an open-access article distributed under the terms of the Creative Commons Attribution License, which permits unrestricted use, distribution, and reproduction in any medium, provided the original author and source are credited. 